\title{
FACTORS ASSOCIATED WITH EXCLUSIVE BREASTFEEDING AMONG MOTHERS IN BANJARMASIN, SOUTH KALIMANTAN
}

\author{
Ema Novita Deniati ${ }^{1}$, Aprizal Satria Hanafi ${ }^{2)}$ \\ 1)Department of Biostatistics, Faculty of Public Health, \\ University of Indonesia \\ 2)Study Program in Public Health, Faculty of Medicine, \\ Lampung Mangkurat University
}

\begin{abstract}
Background: Exclusive breastfeeding is recomended food for infants until the age of 6 months. After 6 months years old a complementary food is recomended until 2 years of age. However, percent of mothers practicing exclusive breastfeeeding is still low. This study aimed to determine factors associated with exclusive breastfeeding among mothers in Banjarmasin, South Kalimantan.

Subjects and Method: This was a quantitative-qualitative study conducted in Banjarmasin, South Kalimantan from June to December 2015. A sample of 258 lactating mothers, consisting of 136 mothers who exclusively breastfed and 122 mothers who did not exclusively breastfeed, were selected for this study by random sampling. The dependent variable was exclusive breastfeeding. The independent variables were maternal age, education, knowledge of exclusive breastfeeding, maternal health condition, maternal work status, and family support. Data were collected by pre-tested questionnaire and interview. Data were analyzed by logistic regression.
\end{abstract}

Results: Low maternal education ( $\mathrm{OR}=0.54 ; 95 \% \mathrm{CI}=0.87$ to $1.82 ; \mathrm{p}=$ 0.005), low maternal knowledge ( $\mathrm{OR}=0.32 ; 95 \% \mathrm{CI}=; \mathrm{p}=0.001$ ), poor maternal health condition ( $\mathrm{OR}=0.23,95 \% \mathrm{CI}=0.08$ to $3.93, \mathrm{p}=0.082$ ), and low family support $(\mathrm{OR}=0.93 ; 95 \% \mathrm{CI}=0.02$ to 8.93; $\mathrm{p}=0.328$ ) were associated with decreased chance of exclusive breastfeeding. Maternal age 2029 years $(\mathrm{OR}=1.76 ; 95 \% \mathrm{CI}=0.18$ to $6.74 ; \mathrm{p}=0.062)$ and housewife $(\mathrm{OR}=$ $1.24 ; 95 \% \mathrm{CI}=1.00$ to $8.29 ; \mathrm{p}=0.123$ ) were associated with increased chance of exclusive breastfeeding. Qualitative study showed that lack of maternal knowledge on the utility of exclusive breastfeeding was a strong predictor for not practicing exclusive breastfeeding. Most of the mothers interviewed believed that providing food in addition to breastmilk could accelerate the growth of their children.

Conclusion: Low maternal education, low maternal knowledge, poor maternal health condition, and low family support are associated with decreased chance of exclusive breastfeeding. Maternal age 20-29 years and housewife are associated with increased chance of exclusive breastfeeding.

Keywords: exclusive breastfeeding, age, education, knowledge, maternal health condition, maternal working status, family support

Correspondence: Ema Novita Deniati. Department of Biostatistics, Faculty of Public Health, University of Indonesia.

Email: emanovitadeniati@gmail.com. 